GUSE et al., v(11), no 11, p. 2351-2356 , JUN, 2013.

Rev. Elet. em Gestão, Educação e Tecnologia Ambiental (e-ISSN: 2236-1170)

\title{
ANÁLISE SÓCIOECONÔMICA E FINANCEIRA DA AGRICULTURA FAMILIAR: UM ESTUDO DE CASO EM CERRO PELADO/URUGUAI
}

\section{SOCIOECONOMIC AND FINANCIAL ANALYSIS OF FAMILY FARMING: A CASE STUDY ON CERRO PELADO / URUGUAY}

\author{
Jaqueline Carla Guse ${ }^{1}$, Andréa Cristina Dorr ${ }^{2}$, Marivane Vestena Rossato ${ }^{3}$, \\ Luiz Antônio Rossi de Freitas ${ }^{4}$ \\ ${ }^{1}$ Universidade Federal de Santa Maria (UFSM) - Aluna do curso de Ciências Contábeis. E-mail: \\ drjaquelinecarla@yahoo.com.br; \\ ${ }^{2}$ UFSM - Profa. Adjunto do Departamento de Ciências Econômicas. E-mail: andreadoerr@yahoo.com.br; \\ ${ }^{3}$ UFSM - Profa. Adjunto do Departamento de Ciências Contábeis. E-mail: marivavest@gmail.com; \\ ${ }^{4}$ UFSM - Prof. Adjunto do Departamento de Ciências Contábeis. E-mail: luizrf@terra.com.br.
}

http://dx.doi.org/10.5902/223611708774

\section{RESUMO}

A agricultura familiar contribui significativamente para a produção de alimentos, geração de renda e o desenvolvimento de todas as regiões, tendo papel fundamental no agronegócio. Neste contexto, o presente trabalho buscou identificar as condições socioeconômicas e financeiras de um agricultor familiar da localidade de Cerro Pelado, interior do município de Riveira/Uruguai. Com a análise desse caso, verificou-se a existência de problemas típicos da agricultura familiar do Brasil, como falta de mão-de-obra, escassez de incentivos públicos, dificuldade de acessos a mercados e alta dependência em relação a intermediários são também os principais problemas no caso da agricultura familiar da região em estudo.

Palavras-chave: agricultura familiar, Cerro Pelado, condições socioeconômicas.

\begin{abstract}
Family farming contributes significantly to food production, income generation and development of all regions, plays a fundamental role in agribusiness. In this context, this study sought to identify the socio-economic and financial conditions of a family farmer from the town of Cerro Pelado, inside the city of Riviera / Uruguay. With the analysis of this case, we verified the existence of typical problems of family farming in Brazil, such as lack of manpower, lack of government incentives, difficulty of access to markets and high dependence on intermediaries are also the main problems in the case of family farming in the region under study.
\end{abstract}

Keywords: family farming, Cerro Pelado, socioeconomic 
GUSE et al., v(11), no 11, p. 2351-2356 , JUN, 2013.

Rev. Elet. em Gestão, Educação e Tecnologia Ambiental (e-ISSN: 2236-1170)

\section{INTRODUÇÃO}

As cadeias produtivas são formadas por relações técnicas, econômicas, sociais e políticas, nas quais o grau de comprometimento entre seus componentes determina sua estrutura e coordenação (BEGNIS et al., 2007). Desse modo, com as constantes transformações ocorridas nos meios de produção e nas relações comerciais da agricultura familiar, o produtor rural é obrigado a desenvolver técnicas de organização da propriedade e de seus negócios. No entanto, conforme afirmam Begnis et al. (2007), mesmo em cadeias com elevado grau de coordenação, e nas quais existe um elevado nível de comprometimento entre os seus componentes, o auto-interesse dos agentes pode levar à sua desarticulação. Isto acontece muitas vezes porque estes estão sujeitos ao oportunismo, que destrói os elos de confiança entre os indivíduos e organizações.

Faz-se necessário conhecer como ocorrem as relações entre os agricultores familiares e seus fornecedores e clientes, e ainda, como estas contribuem no tocante dos custos de transação. Essa necessidade se deve pelo fato da agricultura familiar estar cada vez mais inserida no mercado, e que o crescimento da competição entre os agentes contribuir para que os consumidores passem a exigir produtos diferenciados, que utilizem boas práticas de produção e que possuam preços competitivos.

A comunidade de Cerro Pelado, estabelecida no Departamento de Rivera-Uruguai, encontra-se nacionalmente e internacionalmente reconhecida pelos avanços alcançados em seu território através do trabalho coletivo, sua construção está, de forma geral, vinculada a própria capacidade de trabalhar coletivamente. A comunidade tem como principal fonte de trabalho a agricultura familiar. Conta ainda com uma associação de moradores que visam reunir forças para acessar as políticas públicas que o país promove, buscando desta forma qualidade de vida dos agricultores através da educação, saúde e do desenvolvimento econômico da comunidade.

Este trabalho se justifica pelo fato da agricultura familiar colaborar significativamente para a produção de alimentos, para a geração de renda e para o desenvolvimento de todas as regiões de um país (COSTA, 2010). Com o entendimento da forma que ocorrem as relações comerciais entre os agentes, é possível contribuir para que a pluriatividade agrícola presente na agricultura familiar, com toda sua complexidade implícita, se torne mais competitiva e contribua para a melhoria da qualidade de vida, para a fixação do homem no campo e para um desenvolvimento econômico e ambientalmente sustentável. Neste contexto, este trabalho buscou identificar as condições socioeconômicas e financeiras de um agricultor familiar da localidade de Cerro Pelado, interior do município de Riveira, Uruguai.

O trabalho está estruturado em quatro seções. Após a introdução, têm-se os materiais e métodos utilizados para realização do estudo. Na sequencia, apresenta-se a seção dos resultados, que tem por fim apresentar os resultados obtidos. E por último, as considerações finais.

\section{METODOLOGIA}

Os dados primários foram coletados através da aplicação de questionários semiestruturados em entrevistas realizadas com um produtor familiar da localidade de Cerro Pelado, pertencente ao município de Riveira, Uruguai. O questionário contemplava perguntas 
GUSE et al., v(11), no 11, p. 2351-2356 , JUN, 2013.

REGEXAUFSM

Rev. Elet. em Gestão, Educação e Tecnologia Ambiental (e-ISSN: 2236-1170)

estruturadas e perguntas abertas. Dessa forma, caracteriza-se esta pesquisa como estudos de caso. Os dados secundários foram coletados do sistema jurídico do Uruguai, como, por exemplo, a legislação ambiental do país.

Segundo a literatura consultada, de modo geral, o estudo de caso é aplicável quando se deseja obter generalizações analíticas e não estatísticas, que possam contribuir para um certo referencial teórico. A pesquisa por meio de estudos de caso tem sido enquadrada no grupo de métodos denominados qualitativos e se caracteriza por um maior foco na compreensão dos fatos do que propriamente na sua mensuração. Dessa forma, contrasta-se com os métodos quantitativos, que se preocupam mais em mensurar fenômenos e são aplicados a amostras mais extensas (LAZZARINI, 1997).

Para este trabalho, optou-se pela análise de estudos de caso múltiplos, cuja vantagem é proporcionar evidências inseridas em diferentes contextos, o que acaba tornando a pesquisa como um todo mais robusto. Entretanto, as principais limitações de tais estudos de caso são a subjetividade de análise e a impossibilidade de generalizações das conclusões (YIN, 1989).

Gil (2007) diferencia os instrumentos de coleta de dados mais usuais como questionário, entrevista e formulário. Questionário trata-se de questões respondidas pelo próprio entrevistado, entrevista envolve o entrevistador que formula perguntas ao entrevistado (quando a entrevista for totalmente estruturada, isto é, com perguntas fixas, confunde-se com o formulário) e formulário é a técnica em que o pesquisado responde questões previamente elaboradas pelo pesquisador e este anota as respostas. Segundo Gil (2007), "por ser aplicável aos mais diversos segmentos da população e por possibilitar a obtenção de dados facilmente tabuláveis e quantificáveis, o formulário constitui hoje a técnica mais adequada nas pesquisas de opinião e de mercado".

\section{RESULTADOS E DISCUSSÕES}

Nesta sessão estão apresentados os resultados obtidos com o estudo de caso junto ao produtor rural da comunidade de Cerro Pelado.

\section{Condições socioeconômicas}

O produtor entrevistado possui 53 anos de idade e trabalha a mais de 30 anos com a agricultura e pecuária, sendo a última a principal fonte de renda da família. O casal possui três filhos, dois estudam e residem em outro município e apenas um, de 17 anos, reside na propriedade com os pais e faz curso de eletricidade e informática.

A propriedade possui 60 hectares dos quais somente um hectare não é cultivado, esta se localiza a $78 \mathrm{~km}$ do centro da cidade de Riveira. A casa da família é de alvenaria e possuem também um galpão em que armazenam materiais.

\section{Produção e comercialização}


Rev. Elet. em Gestão, Educação e Tecnologia Ambiental (e-ISSN: 2236-1170)

A família possui 50 cabeças de gado das quais duas vacas de leite são ordenhadas para a fabricação de queijos. Através do programa de fomento do governo uruguaio adquirem $1000 \mathrm{~kg}$ de ração para o gado por ano. Essa ração soma um total, aproximado, de 3.306 pesos uruguaios, ou seja, em torno de US\$185,00. Possuem um ano de carência e mais três anos para efetuarem o pagamento, cuja parcela resulta em aproximadamente US\$ 62,00 por ano. Ressalta-se que o subsídio oferecido pelo governo chega a $80 \%$ do valor total.

Destaca-se que o único incentivo para a atividade é o microcrédito concedido pelo governo do Uruguai com taxa de juros considerada baixa pelos proprietários. Além do gado, possuem ainda um total de 60 ovinos. Através do Projeto Produção Responsável a família conseguiu os bebedores para o gado e auxílio nas instalações de água. O proprietário também comercializa lã de ovinos e couro bovino. O transporte do gado vendido é efetuado através de caminhão sob a responsabilidade do comprador.

A proprietária agroindustrializa alguns produtos, cuja renda é da mesma. Ela destaca a relevância de não precisar pedir recursos financeiros ao marido. Os produtos agroindustrializados são: queijos (total de 20 peças por semana de um kg cada), doces de leite, doces de batata, doces de mandioca, doces de abóbora, rapaduras, pêssegos secos, etc. Os doces são preparados em forno á lenha, sendo que a lenha é retirada dentro da propriedade. Todos estes produtos são comercializados na feira de Cerro Pelado no dia de pagamento das aposentadorias. Nesta feira, outros produtores também comercializam seus produtos.

O queijo é vendido por quilo no valor de 100 pesos uruguaios, aproximadamente, US\$ 6,20 por quilo. Os doces são vendidos em vidros de 200 gramas. O Preço de venda é estimado com base no preço dos outros vendedores. O valor por vidro de doce gira em torno de 70 pesos uruguaios, aproximadamente US\$ 4,30. Os produtos da feira são negociados todos á vista.

A lã produzida é vendida para cooperativas de Riveira, já os bovinos, são comercializado em feiras. A última venda de gado totalizou 15 vacas e cinco terneiros machos. As vacas foram vendidas a US\$ 425,00 e os terneiros a US\$ 270,00 , sendo o pagamento realizado à vista ou a prazo, no último caso o produtor recebe um valor maior. No entanto, toda a negociação é feita sem contratos, ou seja, com base na confiança entre os agentes. Como o pagamento é em dólares, o produtor apenas troca por moeda nacional caso realmente precisar, sendo que o mesmo ressalta que há muitas perdas com o câmbio.

Para a subsistência, o casal produz praticamente os alimentos que consome. Produzem tangerinas, maçãs, milho, feijão, abóbora, batatas, pêras, acerolas, laranjas, pêssegos, amoras, etc. Também produzem hortaliças e verduras orgânicas para o consumo próprio. Quando há excedente das hortaliças, estas são comercializadas na feira junto com os demais produtos. $O$ transporte dos produtos comercializados na feira é feito de automóvel pelo produtor.

Possuem para o serviço dois cavalos e um arado. A mão-de-obra utilizada na propriedade é toda familiar. A necessidade de uma máquina para fazer silagem para os animais foi mencionada como propulsor de melhoria no desenvolvimento da região. Até o presente momento, este serviço é terceirizado e oneroso, às vezes, possuem dificuldades de encontrar alguém para realizá-lo. 
GUSE et al., v(11), no 11, p. 2351-2356, JUN, 2013.

Rev. Elet. em Gestão, Educação e Tecnologia Ambiental (e-ISSN: 2236-1170)

\section{Questões ambientais}

Os dados da pesquisa mostram que a questão ambiental tem uma grande importância para a propriedade em estudo, uma vez que preservam as árvores nativas. Utilizam para consumo somente lenha de eucalipto, além de incentivarem a migração de pássaros e animais em sua propriedade. Observou-se que existe algum conhecimento da legislação ambiental, porém branda e por não haver fiscalizações e punições, suas ações são realizadas, na maioria, por consciência de proteger o meio ambiente e não por ser exigido.

Os produtos naturais consumidos são a água (cerca de 1000 litros por dia) e a lenha de eucalipto. A lenha de eucalipto é mais utilizada no inverno como também para o fogão a lenha no preparo das geleias e doces que são vendidos na feira. Em relação a reciclagem de resíduos, constatou-se que não realizam nenhum tipo de reciclagem. No entanto, a comunidade tem mostrado consciência da importância e está trabalhando em um projeto com este fim.

\section{Gestão da atividade}

Os controles da parte agropecuária são realizados com fins fiscais para entrega da declaração do imposto sobre a renda, além disso, existem controles em cadernos das vendas dos produtos caseiros produzidos. Não há separação dos custos da casa com os custos da agropecuária, foi observado que também não realizam o controle dos custos dos produtos caseiros, uma vez que a maioria das matérias-primas utilizadas é obtida na propriedade. Neste caso, considera-se somente o custo do açúcar. O preço dos produtos agroindustrializados é formado pelas condições de mercado, assim, o preço não é formado com base nos custos de produção. Portanto, fica evidente que a maior preocupação dos proprietários é com a produção, onde somente as atividades agropecuárias são controladas, já o planejamento da produção fica em segundo plano.

\section{Problemas e expectativas futuras}

A seca destaca-se como o principal problema enfrentado na atividade. Em relação aos planos para o futuro, pretendem continuar melhorando e crescendo na atividade, pois os proprietários mostram-se muito satisfeitos na atividade desenvolvida - necessário atribuir uma nota de satisfação entre zero e dez, sendo próximo a zero para pouco satisfeito e próximo a 10 para muito satisfeito, cuja nota atribuída foi 10.

Ressaltam também que falta oferta dos produtos comercializados na feira. Todos os doces e queijos levados à feira são vendidos. Neste caso, poderia vender maior quantidade, caso se disponibilizasse de mais produtos. Dessa forma, não há na região alguém interessado em aprender a agroindustrializar os produtos, pois as mesmas não buscam novas oportunidades de melhoria de vida. Por fim, constatou-se que os filhos não pretendem continuar a atividade desempenhada pelos pais, uma vez que objetivam condições de trabalhos melhores. 
GUSE et al., v(11), no 11, p. 2351-2356, JUN, 2013.

Rev. Elet. em Gestão, Educação e Tecnologia Ambiental (e-ISSN: 2236-1170)

\section{CONCLUSÕES}

A agricultura familiar contribui significativamente para a produção de alimentos, geração de renda e o desenvolvimento de todas as regiões, tendo papel fundamental no agronegócio. Neste enfoque neste trabalho realizou-se um estudo de caso, com o intuito de apresentar um panorama da situação socioeconômica de uma propriedade de agricultura familiar da localidade de Cerro Pelado, no município de Rivera/Uruguai.

Constatou-se que a renda da família estudada advém da agropecuária e da venda de produtos agroindustrializados, como queijo e doces. A gestão da propriedade é apenas para fins fiscais, sendo que apenas as questões agropecuárias são controladas. Destaca-se que apesar da importância do tema, se tem dado pouca ênfase a capacitação gerencial dos empreendedores rurais familiares, de forma a promover a inserção destes no agronegócio nacional.

Além disso, a família, mesmo sem incentivos públicos, tem uma grande preocupação com a questão ambiental. A família utiliza somente lenha de eucalipto e incentiva a migração de pássaros para a propriedade.

Com a análise desse caso, verificou-se que a existência de dificuldades como falta de mão-de-obra, escassez de incentivos públicos, dificuldade de acessos a mercados e alta dependência de intermediários são os principais problemas no caso da agricultura familiar da região em estudo.

\section{REFERÊNCIAS BIBLIOGRÁFICAS}

BEGNIS, H. S. M.; ESTIVALETE, V. de F. B.; PEDROZO, E. A. Confiança, comportamento oportunista e quebra de contratos na cadeia produtiva do fumo no sul do Brasil. Gestão e Produção, São Carlos, v. 14, n. 2, p. 311-322, mai./ago. 2007. Disponível em: <http://www.scielo.br/pdf/gp/v14n2/08.pdf>. Acesso em: 13 mar. 2011.

COSTA, M. L.; LOPES, A. P.; MORAES, C. S.; CICHELERO, M. Gestão Rural Como Agente do Desenvolvimento Regional na Agricultura Familiar. In: XVII Jornadas de Jóvenes Investigadores, 2009, Concordia, Entre Rios. XVII Jornadas de Jóvenes Investigadores: universidad, conocimiento y desarrollo regional. Entre Rios - Argentina : EDUNER, 2009. 